\title{
Unravelling the Molecular Mechanisms Underlying the Protective Effect of Lactate on the High-Pressure Resistance of Listeria monocytogenes
}

\author{
Cristina Serra-Castelló ${ }^{1,+}+\mathbb{D}$, Ilario Ferrocino ${ }^{2,+} \mathbb{D}$, Anna Jofré ${ }^{1} \mathbb{D}$, Luca Cocolin ${ }^{2} \mathbb{D}$, Sara Bover-Cid ${ }^{1, *(\mathbb{D})}$ \\ and Kalliopi Rantsiou ${ }^{2, *}$ \\ 1 IRTA—Food Safety and Functionality Program, Finca Camps i Armet s/n, 17121 Monells, Spain; \\ cristina.serra@irta.cat (C.S.-C.); anna.jofre@irta.cat (A.J.) \\ 2 Department of Agricultural, Forest and Food Science, University of Turin, 10095 Grugliasco, Italy; \\ ilario.ferrocino@unito.it (I.F.); lucasimone.cocolin@unito.it (L.C.) \\ * Correspondence: sara.bovercid@irta.cat (S.B.-C.); kalliopi.rantsiou@unito.it (K.R.) \\ + These authors contributed equally to this work.
}

\section{check for}

updates

Citation: Serra-Castelló, C.;

Ferrocino, I.; Jofré, A.; Cocolin, L.;

Bover-Cid, S.; Rantsiou, K.

Unravelling the Molecular

Mechanisms Underlying the Protective Effect of Lactate on the High-Pressure Resistance of Listeria monocytogenes. Biomolecules 2021, 11, 677. https:/ / doi.org/10.3390/biom11050677

Academic Editors: Marta Lopez Cabo and Francesc Rabanal Anglada

Received: 30 January 2021

Accepted: 27 April 2021

Published: 30 April 2021

Publisher's Note: MDPI stays neutral with regard to jurisdictional claims in published maps and institutional affiliations.

Copyright: (c) 2021 by the authors. Licensee MDPI, Basel, Switzerland. This article is an open access article distributed under the terms and conditions of the Creative Commons Attribution (CC BY) license (https:/ / creativecommons.org/licenses/by/ $4.0 /)$.

\begin{abstract}
Formulations with lactate as an antimicrobial and high-pressure processing (HPP) as a lethal treatment are combined strategies used to control L. monocytogenes in cooked meat products. Previous studies have shown that when HPP is applied in products with lactate, the inactivation of $L$. monocytogenes is lower than that without lactate. The purpose of the present work was to identify the molecular mechanisms underlying the piezo-protection effect of lactate. Two L. monocytogenes strains (CTC1034 and EGDe) were independently inoculated in a cooked ham model medium without and with $2.8 \%$ potassium lactate. Samples were pressurized at $400 \mathrm{MPa}$ for $10 \mathrm{~min}$ at $10^{\circ} \mathrm{C}$. Samples were subjected to RNA extraction, and a shotgun transcriptome sequencing was performed. The short exposure of L. monocytogenes cells to lactate through its inoculation in a cooked ham model with lactate $1 \mathrm{~h}$ before HPP promoted a shift in the pathogen's central metabolism, favoring the metabolism of propanediol and ethanolamine together with the synthesis of the B12 cofactor. Moreover, the results suggest an activated methyl cycle that would promote modifications in membrane properties resulting in an enhanced resistance of the pathogen to HPP. This study provides insights on the mechanisms developed by L. monocytogenes in response to lactate and/or HPP and sheds light on the understanding of the piezo-protective effect of lactate.
\end{abstract}

Keywords: Listeria monocytogenes; pressurization; HPP; organic acids; piezo-resistance

\section{Introduction}

Listeria monocytogenes is a facultative anaerobic Gram-positive pathogen that can cause listeriosis, with several outbreaks being associated with ready-to-eat (RTE) products. The risk assessments developed so far indicate that within the RTE meat products, cooked meat products have to be considered of high risk due to the exposure to recontamination with L. monocytogenes during the preparation of convenient formats (i.e., sliced/diced and packaged) and due to the potential of L. monocytogenes to grow during the refrigerated storage thanks to its psychrotrophic nature [1].

Differences in food safety microbiological criteria regarding L. monocytogenes are found between countries, setting from a maximum of $100 \mathrm{CFU} / \mathrm{g}$ of L. monocytogenes during the shelf-life of the product in EU [2] to the zero-tolerance policy (not detected in $25 \mathrm{~g}$ ) in USA [3]. In this regard, control measures can be implemented by food manufacturers to comply with the legislation by minimizing the prevalence of the pathogen as well as by limiting its growth in contaminated products.

Among all the available control strategies, high pressure processing (HPP) is an emergent non-thermal technology widely applied in the meat industry. HPP is often used 
as a post-lethality treatment (PLT) with the aim of reducing microbial loads in foods that have been exposed to microbial recontamination before their commercialization, i.e., during slicing and packaging operations [4]. Another control measure frequently used by the meat industry to prevent the growth of L. monocytogenes is the use of antimicrobial agents (AMA), especially organic acids and/or their salts [5]. It is known that organic acids in a medium exist in equilibrium between the undissociated and dissociated state, the former being able to cross the cell membrane entering into the cell, where it dissociates liberating anions [6]. The presence of an increased amount of lactate anions inside the cell increases the osmotic pressure and affects the functioning of the cell metabolism, thus resulting in an impaired bacterial growth.

In some cases, the combined application of HPP and organic acid salts is chosen by the food industry in order to comply with the highest level of control of L. monocytogenes requested in Alternative 1 (combination of a PLT and an AMA) under the requirements of zero tolerance policy of USA [3]. According to the hurdle technology concept described by Leistner [7], the intelligent combination of hurdles (as sub-lethal stresses) leads to an increased effectiveness in controlling L. monocytogenes survival/growth. However, crossprotection of a sublethal stress against subsequent treatments can also occur, damaging cells without killing them [8]. Few studies have been conducted dealing with the effect of combination of strategies (i.e., HPP and organic acids) on L. monocytogenes in meat products [4,9]. Interestingly, Serra-Castelló et al. [10] showed that the HPP inactivation of three L. monocytogenes strains (CTC1034, CTC1011 and Scott A) in cooked ham formulated with potassium lactate was lower than in cooked ham without this antimicrobial. This piezo-protective effect was quantified showing it was strain and lactate dose-dependent. Additionally, in cooked meat products, L. monocytogenes surviving HPP was found to grow at higher rate compared to non-pressurized L. monocytogenes during the storage of the products [11], such piezo-stimulation effect was enhanced in products formulated with lactate [11].

The present study aimed to investigate by means of transcriptomics the molecular mechanisms underlying the piezo-protective effect exerted by lactate on L. monocytogenes HPP inactivation in a cooked ham model medium.

\section{Material and Methods}

\subsection{Cooked Ham Model Medium Formulation and Characterization}

Cooked ham model medium (CHMM) was prepared with Brain Heart Infusion (BHI) broth (Beckson Dickinson, Sparks, MD, USA) and the addition of the following ingredients ( $\mathrm{g} / \mathrm{L})$ usually used in the manufacture of cooked ham from pork meat: sodium chloride, 15.7; dextrose, 5.77; sodium ascorbate, 0.6 ; and sodium nitrite, 0.1 . The medium was sterilized at $121{ }^{\circ} \mathrm{C}$ for $20 \mathrm{~min}$. In order to have samples without organic acids (control) and with lactate, two lots of CHMM were prepared: without and with $2.8 \%(v / v)$ potassium lactate (using HiPure P Plus, Corbion@ ( Montmeló, Spain, known to have $76-80 \%$ w/w of potassium lactate).

\subsection{L. monocytogenes Strains and Pre-Culture Conditions}

Strains of L. monocytogenes used in the present study included two different serotypes with relevance from the clinical and from the food and food processing environment perspective [12]. The meat isolate CTC1034 (serotype 4b) from the IRTA Food Safety Program's collection and previously used in studies dealing with the application of HPP in meat products $[10,11,13,14]$ and the L. monocytogenes strain EGDe (serotype 1/2a) as a reference strain. For this study, three biological replicates of each strain were prepared from $-80{ }^{\circ} \mathrm{C}$ stock cultures.

L. monocytogenes strains CTC1034 and EGDe were refreshed into $8 \mathrm{~mL}$ of BHI broth for $7 \mathrm{~h}$ at $37^{\circ} \mathrm{C}$. Afterwards, $1 \%(v / v)$ were consecutively subcultured in $200 \mathrm{~mL}$ of fresh BHI at $37^{\circ} \mathrm{C}$ for 14 and $24 \mathrm{~h}$, respectively, in order to standardize the strains at the early stationary 
phase. After incubation, cultures were preserved frozen at $-80{ }^{\circ} \mathrm{C}$ supplemented with $20 \%$ of glycerol until used [15].

\subsection{Preparation of the Samples and HPP}

For each biological replicate, cultures of L. monocytogenes strains CTC1034 and EGDe were thawed at ambient temperature and centrifuged at $8240 \times \mathrm{g}$ for $7 \mathrm{~min}$ at $12{ }^{\circ} \mathrm{C}$. Supernatants were discarded and cell pellets were resuspended in the same volume of CHMM without or with $2.8 \%$ of lactate. Cultures were distributed in $4 \times 10 \mathrm{~cm} \mathrm{PA} / \mathrm{PE}$ pouches (oxygen permeability of $50 \mathrm{~cm}^{3} / \mathrm{m}^{2} / 24 \mathrm{~h}$ and a low water vapor permeability of $2.8 \mathrm{~g} / \mathrm{m}^{2} / 24 \mathrm{~h}$; Sistemvac, Estudi Graf S.A., Girona, Spain), which were closed by thermosealing. Cultures were kept for $1 \mathrm{~h}$ at $10^{\circ} \mathrm{C}$ to allow the adaptation of L. monocytogenes cells in CHMM medium without and with $2.8 \%$ of lactate. Half of the samples were subsequently pressurized at $400 \mathrm{MPa}$ for $10 \mathrm{~min}$ using an industrial HPP equipment (Wave 6000; Hiperbaric, Burgos, Spain). The come-up time was $2.50 \mathrm{~min}$ and the pressure release time was almost immediate $(<2 \mathrm{~s})$. The pressurization fluid was water and the initial temperature was set at $10{ }^{\circ} \mathrm{C}$. After pressurization, samples were kept for $30 \mathrm{~min}$ at $10^{\circ} \mathrm{C}$ before L. monocytogenes enumeration and RNA extraction. Non-pressurized samples were kept at $10^{\circ} \mathrm{C}$ until analysis together with the HPP samples.

\subsection{L. monocytogenes Enumeration and Data Analysis}

For each treatment and biological replicate, L. monocytogenes concentration was determined by plate colony count method from the appropriate tenfold serial dilution prepared in $0.1 \%$ Bacto Peptone (Difco Laboratories, Detroit, MI, USA) with $0.85 \% \mathrm{NaCl}$. Samples were spread on CHROMagar ${ }^{\mathrm{TM}}$ Listeria (CHROMagar, Paris, France) and incubated at $37^{\circ} \mathrm{C}$ for $48 \mathrm{~h}$ according to the manufacturer instructions. Chromogenic media for L. monocytogenes are known to be able to recover high pressure injured L. monocytogenes [16,17]. In any case, plates were further checked after additional $24-48 \mathrm{~h}$ to make sure that sub-lethally injured cells had time to recover and form colonies and, thus, minimize the overestimation of the lethal effect of HPP $[10,11]$. L. monocytogenes counts were Log transformed, and the inactivation value in terms of Log reduction was calculated by subtracting from the counts found in non-pressurized cultures $\left(\log \mathrm{N}_{0}\right)$ those of the pressurized cultures $(\log \mathrm{N})$, i.e., $\log N_{0}-\log N=\log N_{0} / N$, both in the control and 2.8\%-lactate lots.

\subsection{Nucleic Acid Extraction and Sequencing}

DNA of the samples prepared according to Section 2.3 was extracted from L. monocytogenes strain CTC1034 by using $1 \mathrm{~mL}$ of an overnight culture of BHI centrifuged at $14,000 \times g$ for $10 \mathrm{~min}$. The pellet was then used for DNA extraction according to the protocol described in Cocolin et al. [18]. DNA was quantified using the QUBIT DS-HS kit (Thermo Fisher Scientific, Milan, Italy) and it was standardized at $50 \mathrm{ng} / \mu \mathrm{L}$. Whole genome sequencing (WGS) was performed using NEBNext ${ }^{\circledR}$ library prep Kit according to the manufacturers instructions in paired-end ( $2 \times 150 \mathrm{bp})$ on a NextSeq 550 Illumina system by the Novagene Company (Cambridge, United Kingdom).

For the transcriptomic analysis, L. monocytogenes cultures of CTC1034 and EGDe strains were centrifuged at $10,416 \times g$ for $5 \mathrm{~min}$ at $10^{\circ} \mathrm{C}$ and pellets corresponding to $3.6 \mathrm{~mL}$ of culture were resuspended with $125 \mu \mathrm{L}$ of RNAlater solution (Invitrogen, Thermo Fisher Scientific, Barcelona, Spain,) and kept at $-80^{\circ} \mathrm{C}$. Total RNA was extracted from the pellets using the RNeasy PowerMicrobiome Kit (QIAGEN, Hilden, Germany) following the manufacturers' instructions, and residual DNA was removed with TURBO DNase (Invitrogen, Thermo Fisher Scientific, Milan, Italy) according to the manufacturers' instructions. RNA concentrations were quantified by using a Nanodrop Instrument (Spectrophotometer ND1000, Thermo Fisher Scientific, Milan, Italy). The RNA integrity was verified by agarose gel electrophoresis. The RNA sequencing library preparation and cDNA synthesis were performed using the NEBNext Ultra RNA Library Prep Kit according to the manufacturers' instructions at Genewiz Inc. (Leipzig, Germany). The transcriptome was studied for all the 
samples from the experiment and sequencing was carried out on a NextSeq 550 Sequencer yielding $150 \mathrm{bp}$ paired-end reads.

\subsection{Bioinformatics and Data Analysis}

WGS of L. monocytogenes strains CTC1034 led to 5,484,770 paired-end reads. Lowquality bases (Phred score $<20$ ) were trimmed, and reads shorter than $60 \mathrm{bp}$ were discarded using the SolexaQA++software v3.1.7.1 and PRINSEQ v0.20.4, respectively [19,20]. Reads were assembled using SPAdes v3.14.1 [21]; genes were annotated with Prokka v 1.14.5 [22] and used to build the reference database. A draft genome of L. monocytogenes EGDe (NC_003210.1) was downloaded from NCBI (BioProject: PRJNA61583), and genes were annotated with Prokka. The pangenome calculation and phylogenetic analysis of L. monocytogenes strains were obtained by Roary v. 3.11.2 [23].

In order to investigate the molecular background that could explain the observed differences in the inactivation between the two L. monocytogenes strains as well as the piezoprotective effect of lactate, a transcriptomic approach was implemented. Total RNA was extracted, sequenced, and compared between L. monocytogenes cultures shortly exposed to (i) CHMM (control without HPP), (ii) CHMM supplemented with lactate (without HPP), (iii) CHMM and subjected to HPP, and (iv) CHMM supplemented with lactate and subjected to HPP.

Raw reads were quality filtered by SolexaQA++ software and PRINSEQ (Phred score $<20,<60 \mathrm{bp}$ ). Reads were aligned against the respective build database by using Bowtie2 in end-to-end, sensitive mode according to the strain used. The number of reads mapped to each gene (.sam files) were then used for KEGG functional analysis using MEGAN6 software [24]. Data normalization and determination of differentially abundant KEGG genes, among the studied conditions (lactate and HPP, alone, or in combination) or strains, were conducted using the Bioconductor DESeq2 package [25] in the statistical environment R [26] with default parameters. The statistical significance ( $p$-values) was adjusted for multiple testing using the Benjamini-Hochberg procedure, which assesses the false discovery rate (FDR) by using the DESeq2 package.

Gene set enrichment for pathway analysis was then performed on KEGG orthologs table imported in the GAGE Bioconductor package [27] to identify biological pathways overrepresented or underrepresented between sample without lactate and without HPP treatment against the other combination.

\subsection{Availability of Data and Material}

WGS and Metatranscriptomic raw sequence reads were deposited at the Sequence Read Archive of the National Center for Biotechnology Information (Bioproject accession number: PRJNA692371 and PRJNA692360, for L. monocytogenes CTC1034 and EGDe, respectively).

\subsection{Fatty Acid Profile of L. monocytogenes}

For the strain CTC1034 the fatty acid profile was analyzed to confirm potential changes in the membrane composition due to exposure to lactate and/or HPP. For this, samples of $L$. monocytogenes CTC1034 were centrifuged at $10,416 \times g$ for $6 \mathrm{~min}$ at $10{ }^{\circ} \mathrm{C}$. Supernatant was discarded and pellets were resuspended in $1 \mathrm{~mL}$ of purified water. Cells were disrupted with $0.5 \mathrm{~g}$ of glass beads in a mixer mill (Mixer Mill MM200, Retsch, Llanera, Spain) for $5 \mathrm{~min}$ at $30 \mathrm{~Hz}$, centrifuged and supernatant was discarded. Pellets were frozen at $-20{ }^{\circ} \mathrm{C}$ for $2 \mathrm{~h}$ before being freeze dried (Lyomicron LM-181004, Coolvacuum, Granollers, Spain). Methyl esters of fatty acids (FAME) were obtained by methylation described by Castro-Gómez et al. [28], using tritridecanoine as an internal standard. FAME analysis was carried out on an Autosystem chromatograph (Perkin Elmer, Beaconsfield, UK) fitted with a VF-23ms, fused silica capillary column $(30 \mathrm{~m} \times 0.25 \mathrm{~mm}$ i.d. $\times 0.25 \mu \mathrm{m}$ film thickness, Varian, Middelburg, The Netherlands) and FID, according to Calvo et al. [29]. The statistical difference of the results among conditions was assessed through the MANOVA test. 


\section{Results and Discussion}

\subsection{Inactivation of L. monocytogenes by HPP}

Inactivation of L. monocytogenes strains CTC1034 and EGDe submitted to HPP at $400 \mathrm{MPa}$ for $10 \mathrm{~min}$ in the CHMM resembling the composition of a cooked ham, with or without potassium lactate, is shown in Figure 1. The results show that the application of HPP in a medium without lactate inactivated CTC1034 and EGDe strains by an average reduction of $1.17 \pm 0.20$ and $2.96 \pm 0.43 \mathrm{Log}$ units, respectively. Thus, the strain CTC1034 was significantly $(p<0.05)$ more resistant to HPP than EGDe. In the presence of lactate in the CHMM, HPP resulted in a lower inactivation of the strains, recording $0.44 \pm 0.04$ and $2.36 \pm 0.22 \mathrm{Log}$ reduction for CTC1034 and EGDe, respectively. In particular, for the CTC1034 strain, the lethal effect of HPP was lower $(p<0.05)$ in the presence of lactate, corroborating the piezo-protective effect of this antimicrobial on L. monocytogenes inactivation as previously shown for this and other strains inoculated in different types of meat products $[9,10,30,31]$.

\section{CTC1034}

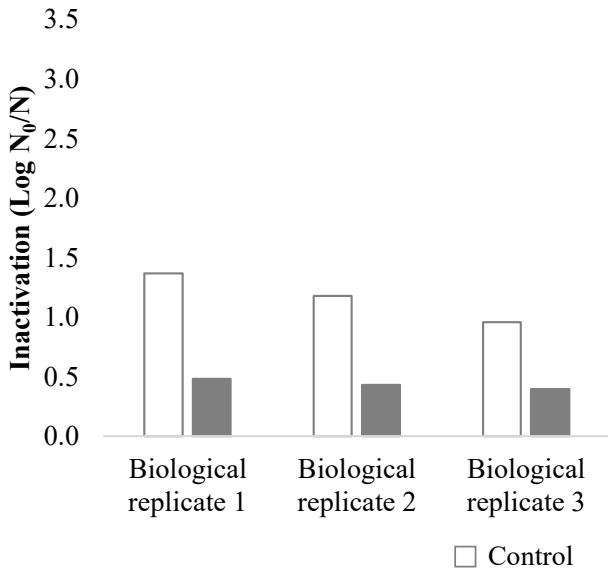

EGDe

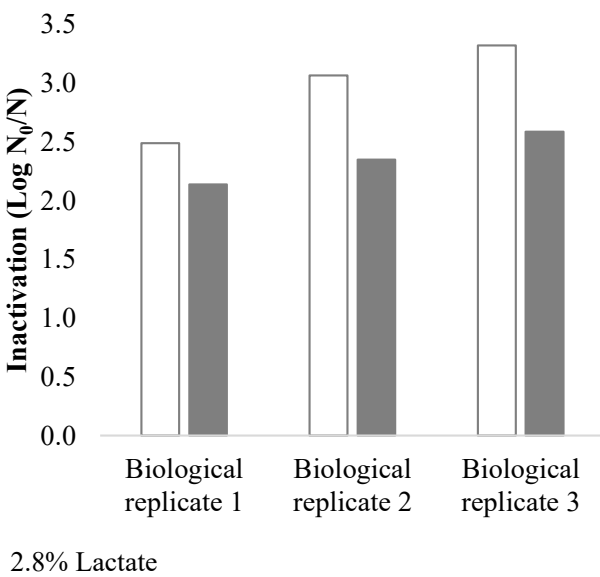

Figure 1. Inactivation ( $\log \mathrm{N}_{0} / \mathrm{N}$ ) of each biological replicate of the L. monocytogenes CTC1034 and EGDe strains observed after HPP (400 MPa for $10 \mathrm{~min}$ ) in cooked ham model medium without (control) and with $2.8 \%(v / v)$ potassium lactate.

3.2. Analysis of RNA-Seq Results. KEGG Annotation Classification and Pathway Enrichment Analysis of the DEGs

3.2.1. Comparison of L. monocytogenes CTC1034 and EGDe Genomes

WGS sequencing of L. monocytogenes CTC1034 showed a total of 19 contigs that provide a total genome length of 2,943,406 bp with an average GC content of $38.05 \%$. Sequencing revealed the presence of $2958 \mathrm{CDS}, 1 \mathrm{tmRNA}$ and $61 \mathrm{tRNA}$ encoding genes.

The comparison of L. monocytogenes genomes of CTC1034 and EGDe strains showed the presence of 2967 core genes including 394 genes encoding hypothetical proteins. Only 77 genes were absent or present in one L. monocytogenes strain compared to the other, 35 genes being found in CTC1034 but not in EGDe and 42 being found in EGDe but not in CTC1034. Most of the 35 genes found in CTC1034, but not in EGDe, were related to transcription factors, while the major fraction of genes found in EGDe were involved in protein export and transcription factors. As transcription factors regulate gene expression, a greater abundance in the CTC1034 could be related to the major resistance to HPP stress this strain has shown [32].

\subsubsection{Whole Transcriptome Analysis}

For the transcriptomic analysis involving both L. monocytogenes strains, a total of $152.43 \mathrm{Gbp}$ of clean reads were obtained. For each sample, approximately $6.62 \mathrm{Gbp}$ of reads 
were found (Supplementary Table S1). The KEGG analysis assigned 864 genes to 24 KEGG pathways.

Results from the statistical analysis of the KEGG genes obtained with the transcriptomic analysis revealed that the number of differentially expressed genes (DEGs) found in the pairwise comparisons between all the condition combinations studied (effect of lactate, effect of HPP and effect of both factors) was strain-dependent (Figure 2; Supplementary Tables S2-S10).

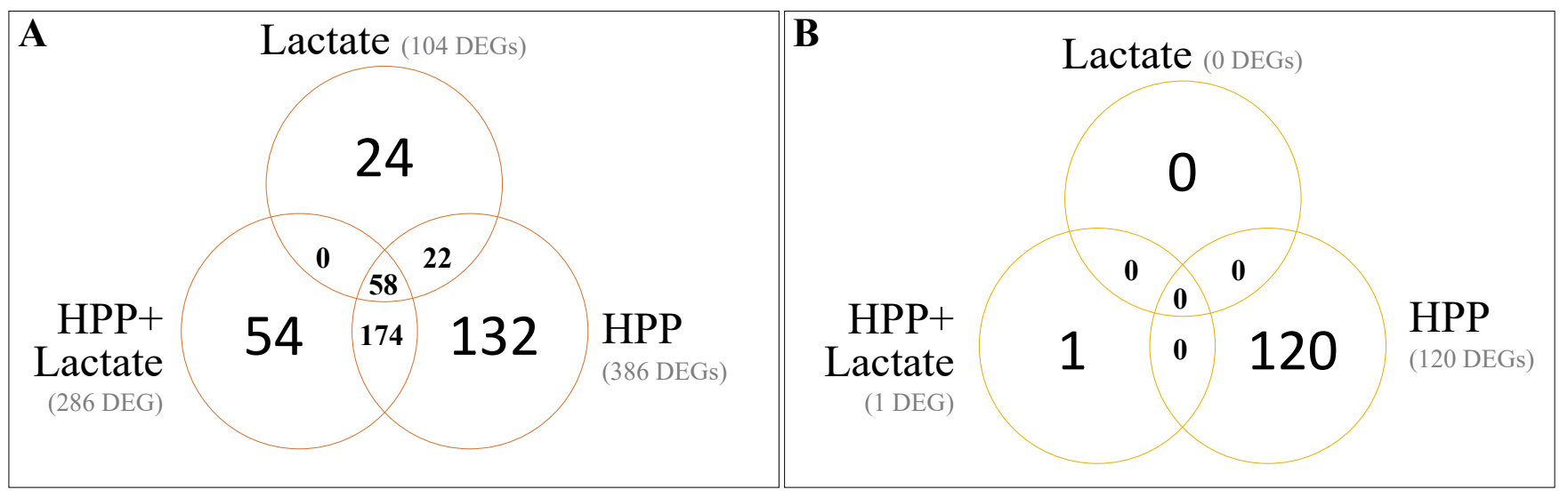

Figure 2. Venn diagrams of differentially expressed genes (DEGs) of L. monocytogenes strains CTC1034 (A) and EGDe (B) due to the exposure of cells to lactate, the application of the HPP (400 MPa for $10 \mathrm{~min}$ ) and the application of both stresses compared to control conditions (exposed to CHMM without lactate).

In this framework, the stress induced by the exposure of L. monocytogenes cultures to CHMM with lactate compared to those exposed to CHMM without the antimicrobial resulted in a different response depending on L. monocytogenes strain. While the presence of lactate in the CHMM resulted in 104 DEGs in CTC1034, no DEGs were found in EGDe (Figure 2; Supplementary Table S3). A similar pattern was obtained when analyzing the effect of the application of both stresses, lactate and HPP, on L. monocytogenes compared to control conditions, resulting in 286 DEGs for the CTC1034 and only 1 DEGs for the EGDe strain (Figure 2; Supplementary Tables S6 and S10). Therefore, these results suggest that the response to stress is highly dependent on the particularities of the L. monocytogenes strain. In the study of the transcriptional response of two L. monocytogenes strains due to exposure to organic acids (lactate and diacetate) reported by Stasiewicz et al. [33], large differences on the number of transcribed genes were found and only a minor fraction of the differentially transcribed genes were shared between the two strains.

Additionally, it was interesting to observe that DEGs found for EDGe in the pairwise comparison of pressurized samples with and without the presence of lactate (Supplementary Table S8) were the same or involved in the same metabolic pathways as those DEGs found in non-pressurized cultures of CTC1034 in response to lactate stress (Supplementary Table S3). The different pairwise comparisons between the stressing conditions involving lactate also support this hypothesis (Supplementary Tables S4, S5, S8 and S9). These results would lead to the hypothesis that both L. monocytogenes strains employ similar molecular mechanisms in response to the lactate stress, although they seem to be activated in a different magnitude and/or time frame.

On the other hand, the application of the HPP resulted in 386 and 120 DEGs for the CTC1034 and EGDe strains, respectively, when compared to control conditions, i.e., L. monocytogenes cultures exposed to CHMM without lactate (Figure 2; Supplementary Tables S2 and S7).

The pathway enrichment analysis (performed by GAGE) of the KEGG genes of CTC1034 strains showed an enrichment of several pathways in CHMM subjected to HPP (with and without lactate) compared with the control CHMM (without HPP nor lactate), including Flagellar assembly (ko02040), Fructose and mannose metabolism (ko00051), Phosphotransferase system (ko02060), Biosynthesis of amino acids (ko01230) and Pheny- 
lalanine, and tyrosine and tryptophan biosynthesis (ko00400). Moreover, an enrichment of the flagellar assembly (ko02040) and a reduction in glycolysis/gluconeogenesis (ko00010) in CHMM supplemented with lactate without HPP was observed when compared with CHMM. Regarding EGDe, an enrichment in cysteine and methionine metabolism (ko00270), peptidoglycan biosynthesis (ko00550), fatty acid metabolism (ko01212), biosynthesis of amino acids (ko01230) and citrate cycle (ko00020), and a downregulation of the flagellar assembly (ko02040) and phosphotransferase system (PTS) (ko02060) were observed in CHMM subjected to HPP if compared with non-pressurized CHMM (data not shown).

\subsubsection{Effect of Lactate Exposure on L. monocytogenes}

Some studies support that in order to counteract the intracellular osmotic pressure caused by an increased amount of lactate, bacteria (i) reduce intracellular pools of anions and (ii) shift the flux in the central carbon metabolism [34]. The results from the present transcriptomic analysis reveal that L. monocytogenes could use both strategies to overcome the stress suffered by its exposure to lactate. Regarding the possible effect of lactate on the central carbon metabolism of the pathogen, the results of the present study show that genes involved in the pentose phosphate pathway coupled with oxidative reactions to produce reducing equivalents ( $r p i B, t k t A, t k t B, G 6 P D)$ were upregulated. Additionally, a downshift was observed in the conversion of pyruvate to acetyl-CoA and ethanol, as indicated by the downregulation of genes such as $p d h C, p l f D$, and $a d h E$. In line with the output of the pathway enrichment analysis described above, these transcriptomic results suggest that in presence of lactate, L. monocytogenes redistributed its metabolic carbon flux from the glycolytic pathway to oxidative reactions producing reducing equivalents (Figure 3).

Genes of other metabolic pathways that are source of reducing equivalents were also upregulated (Figure 3). In this framework, genes involved in the synthesis of cobalamin and corrinoid cofactors and B12 cofactor (adenosylcobalamin) (CbiK-CbiX, CbiL, CobI, $\mathrm{CbiH}, \mathrm{CobJ}, \mathrm{CbiF}, \mathrm{CobM}, \mathrm{CbiD}, \mathrm{CbiT}, \mathrm{CbiC}, \mathrm{CobH}, \mathrm{CbiA}, \mathrm{CobB}, \mathrm{CbiB}, \mathrm{CobC}, \mathrm{CobD}, \mathrm{CobU}, \mathrm{CobS}$, $\mathrm{CobV}$, and $E u t T)$, which consist of reductive reactions, were also found to be upregulated (Supplementary Tables S3 and S8). In addition, the higher expression of genes related to the cobalamin and corrinoid pathways is coordinated with the upregulation of the genes involved in the 1,2 propanediol $(P d u C, P d u D, P d u E, P d u P, P d u Q, P d u L P d u W)$ and ethanolamine metabolism (EutH, EutA, EutB, EutC, EutQ, EutN, EutJ, EutT, EutL) found in the presence of lactate (Supplementary Tables S3 and S8), since both pathways are regulated by the cofactor B12 riboswitch in L. monocytogenes, the synthesis of the cofactor B12 being required for the metabolism of these pathways [35]. Such coordination is biologically relevant since the B12 cofactor is required in the catabolic pathways of ethanolamine and propanediol degradation. Moreover, genes involved in the catabolism of rhamnose ( $r h a A$, $r h a B$, dhal and $g l p K)$ were upregulated, suggesting that it can be used as a carbon source for the 1,2 propanediol pathway [36]. The use of 1,2 propanediol and ethanolamine as a carbon source has been reported to provide a competitive advantage to L. monocytogenes under diverse conditions such as when growing in vacuum-packaged smoked salmon [37] or when co-cultured with other bacteria [38]. In the present study the role of 1,2 propanediol and ethanolamine metabolism in the piezo-protective effect of lactate on L. monocytogenes could not be directly elucidated, but they are important metabolites that provide a fitness advantage to L. monocytogenes [39]. 


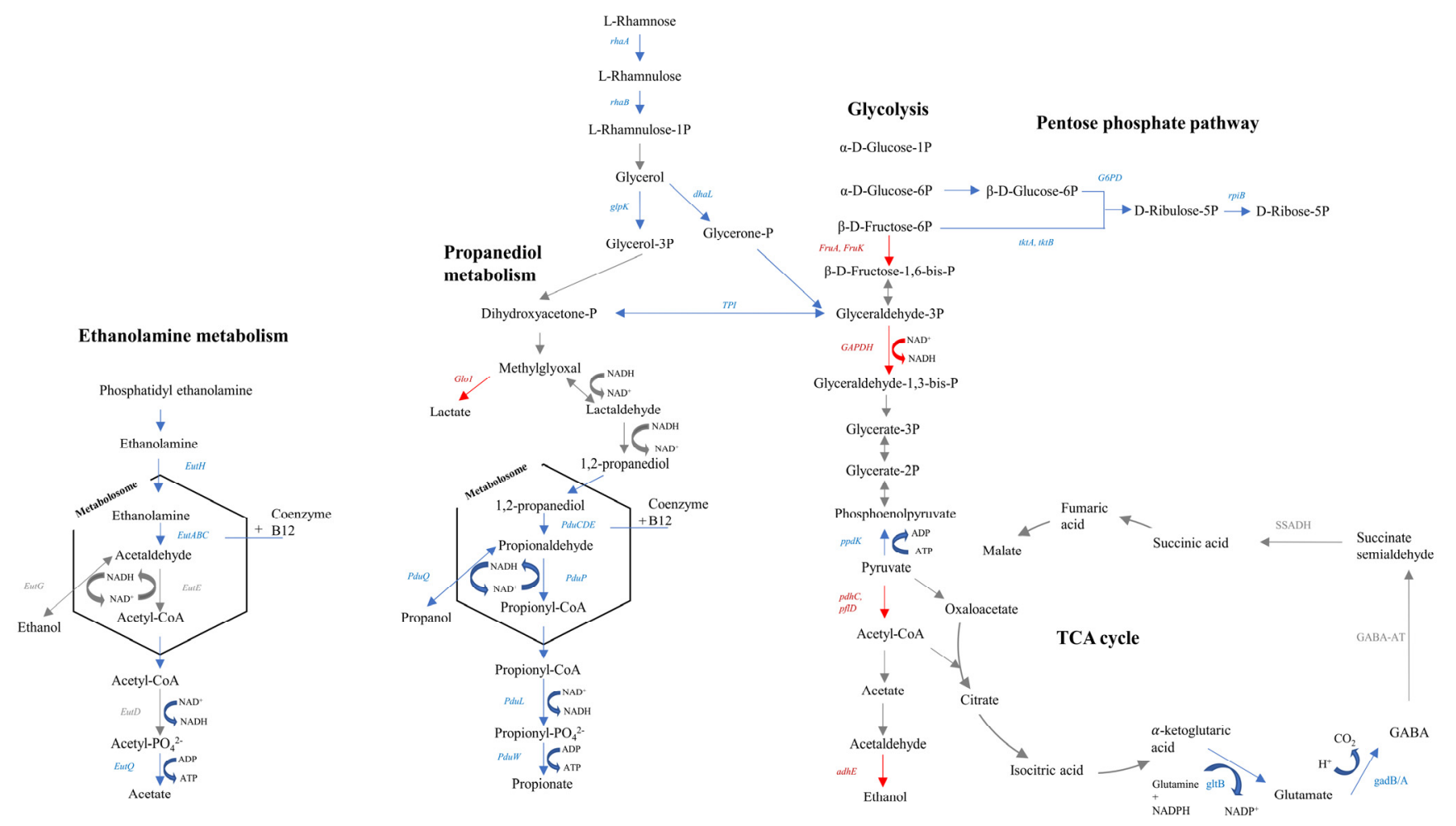

Figure 3. Predicted carbon flux in L. monocytogenes CTC1034 and EGDe when exposed to lactate. Blue, red, and grey arrows and text indicate genes that were upregulated, downregulated, or were not differentially expressed, respectively. Genes and proteins: $E u t H$, ethanolamine transporter; EutA, ethanolamine transporter protein EutA; EutB, ethanolamine ammonia-lyase large subunit; EutC, ethanolamine ammonia-lyase small subunit; EutG, alcohol dehydrogenase; EutE, aldehyde dehydrogenase; EutD, phosphotransacetylase; EutQ, ethanolamine utilization protein EutQ; Glo1, lactoylglutathione lyase; $P d u C$, propanediol dehydratase large subunit; $P d u D$, propanediol dehydratase medium subunit; $P d u E$, propanediol dehydratase small subunit; $P d u P$, propionaldehyde dehydrogenase; $P d u Q, 1$-propanol dehydrogenase; $P d u L$, phosphate propanoyltransferase; $P d u W$, propionate kinase; TPI, triosephosphate isomerase; FruA, fructose PTS system EIIBC; FruK, 1-phosphofructokinase; GAPDH, glyceraldehyde 3-phosphate dehydrogenase; $p p d K$, pyruvate orthophosphate dikinase; $p d h C$, pyruvate dehydrogenase E2 component; $p f l D$, formate C-acetyltransferase; adhE, acetaldehyde dehydrogenase/alcohol dehydrogenase; $t k t A$, $t k t B$, transkelotase; G6PD, glucose-6-phosphate 1-dehydrogenase; RpiB, ribose 5-phosphate isomerase B; DhaL, phosphoenolpyruvate-glycerone phosphotransferase subunit DhaL; GlpK, glycerol kinase; RhaB, rhamnulokinase; RhaA, L-rhamnose isomerase; gltB, glutamate synthase; gadB/A, glutamate descarboxylase; $G A B A-A T$, GABA aminotransferase; $S S A D H$, succinate semialdehyde dehydrogenase

Together with lactate anions, protons are also accumulated inside the cell, with the consequent disruption of bacterial transmembrane potential. In this framework, one of the strategies frequently used by bacteria to restore intracellular $\mathrm{pH}$ homeostasis and/or maintain transmembrane potential is the metabolism of glutamate [40,41]. The intracellular decarboxylation of glutamate by a glutamate decarboxylase enzyme to form aminobutyric acid (GABA) results in the consumption of one proton, contributing to restore the intracellular $\mathrm{pH}$ [42]. The upregulation of genes involved in the metabolism of glutamate $(\operatorname{gad} A B$, gltBD) pointed out that L. monocytogenes could use this strategy to restore intracellular $\mathrm{pH}$ homeostasis disturbed when exposed to lactate (Figure 3; Supplementary Tables S3 and S8).

The enrichment of flagellar assembly pathways and in detail of flagellar genes (FlhA, FlhF , FliC, FliE, FliF, FliG, FliH, FliI, FliR, FliP , FlgB , FlgC, FlgD , FlgE , FlgG, FlgK, and FlgL) found in the presence of lactate (Supplementary Tables S3 and S8) could indicate that the electrochemical potential of protons across the cytoplasmic membrane could also contribute to fuel the flagellar motor of the pathogen [43] and/or that the unfavorable environment faced by L. monocytogenes would promote the pathogen to elicit the chemotactic response and to move to a more favorable environment [44]. 
The activation of all the strategies to counteract the osmotic pressure and membrane potential changes due to lactate would result in less efficient pathways for ATP production and in a higher energy expenditure, leading to the limitation of growth in the presence of lactate [45-47]. A decrease of metabolic energy generation due to the increase in external lactate concentration was described in Streptococcus cremoris [48].

In addition to the up/downregulation of molecular mechanisms involved in restoring osmotic pressure and membrane potential, it is worth to highlight that in the presence of lactate, L. monocytogenes specifically upregulated genes involved in the methionine synthesis (Figure 4), in particular a higher expression of the methyltransferases mmuM in CTC1034 (Supplementary Table S3) and MetE in pressurized EGDe (Supplementary Table S8) was found. Both enzymes are responsible for converting homocysteine to methionine, thus suggesting that in the presence of lactate L. monocytogenes promoted the oxidation of homocysteine to methionine, avoiding the accumulation of the toxic metabolite homocysteine and increasing the amount of intracellular methionine. In accordance with this, genes associated with the sulfur metabolism (metC, met $X, c y s E$ or $c y s O)$ involved in the methionine synthesis were also found to be upregulated by the exposure of L. monocytogenes to lactate (Figure 4; Supplementary Tables S3 and S8). In previous studies dealing with the transcriptome analysis of L. monocytogenes cells exposed to lactate, the upregulation of the methionine biosynthesis was not reported [33,49]. However, in those experiments L. monocytogenes was exposed to lactate for a much longer time, i.e., $8 \mathrm{~h}$ at $7^{\circ} \mathrm{C}$ and $48 \mathrm{~h}$ at $15^{\circ} \mathrm{C}$, than the exposure time used in the present study $\left(<2 \mathrm{~h}\right.$ at $\left.10^{\circ} \mathrm{C}\right)$. It can be hypothesized that the upregulation of the methionine synthesis would only occur in the early exposure of the pathogen to lactate as a first step of the overall mechanism to overcome the stress suffered by the presence of lactate. In addition to the time-related factor, other potential reasons leading to different results include the pathogen strains, the concentration and the type of salt (sodium vs. potassium), and the incubation temperature or the matrix composition (culture medium) used for the experiment.

Among all the multiple factors that can determine the expression of genes involved in the methionine synthesis, the observed upregulation of this metabolic pathway by $L$. monocytogenes in the presence of lactate could be relevant in relation to the piezo-resistance mechanisms since another organic acid such as acetate has been shown to specifically inhibit the synthesis of methionine in Escherichia coli, favoring the accumulation of the toxic compound homocysteine and consequently limiting or even inhibiting the growth of the pathogen [50]. Moreover, Roe et al. [50] reported that the addition of methionine in the medium containing acetate restores E. coli growth to $80 \%$ of that observed in medium without acetate, indicating that the inhibition of the methionine biosynthesis is one of the main factors responsible for the growth depletion of E. coli cultured in the presence of acetate. Supporting these results, Pinhal et al. [51] reported that the uncoupling effect of acetate or the perturbation of the anion composition of the cell played only a limited role $(20 \%)$ in the E. coli growth depletion, suggesting that other molecular mechanisms, such as the inhibition of the methionine synthesis, could have a more prominent role on the bacterial growth-inhibitory effect.

Methionine can be converted to S-adenosyl-L-methionine (SAM), which represents a methyl group donor for many fundamental cellular processes, such as cellular signaling and epigenetic regulations that promote cellular anabolism and proliferation in bacteria and yeasts [52,53]. Specifically, SAM is involved in the methylation of proteins, RNAs, biotin, polyamines, and lipids [53,54]. In the present study, the metK gene responsible for the conversion of methionine to SAM was found to be upregulated in the L. monocytogenes CTC1034 strain when it was exposed to lactate, suggesting a higher production of SAM. Moreover, an increased intracellular concentration of methionine was also reported to contribute to the antioxidant defense in bacteria [55], although its role in the piezo-protection remains unknown. 


\section{Sulfur metabolism and cysteine biosynthesis}

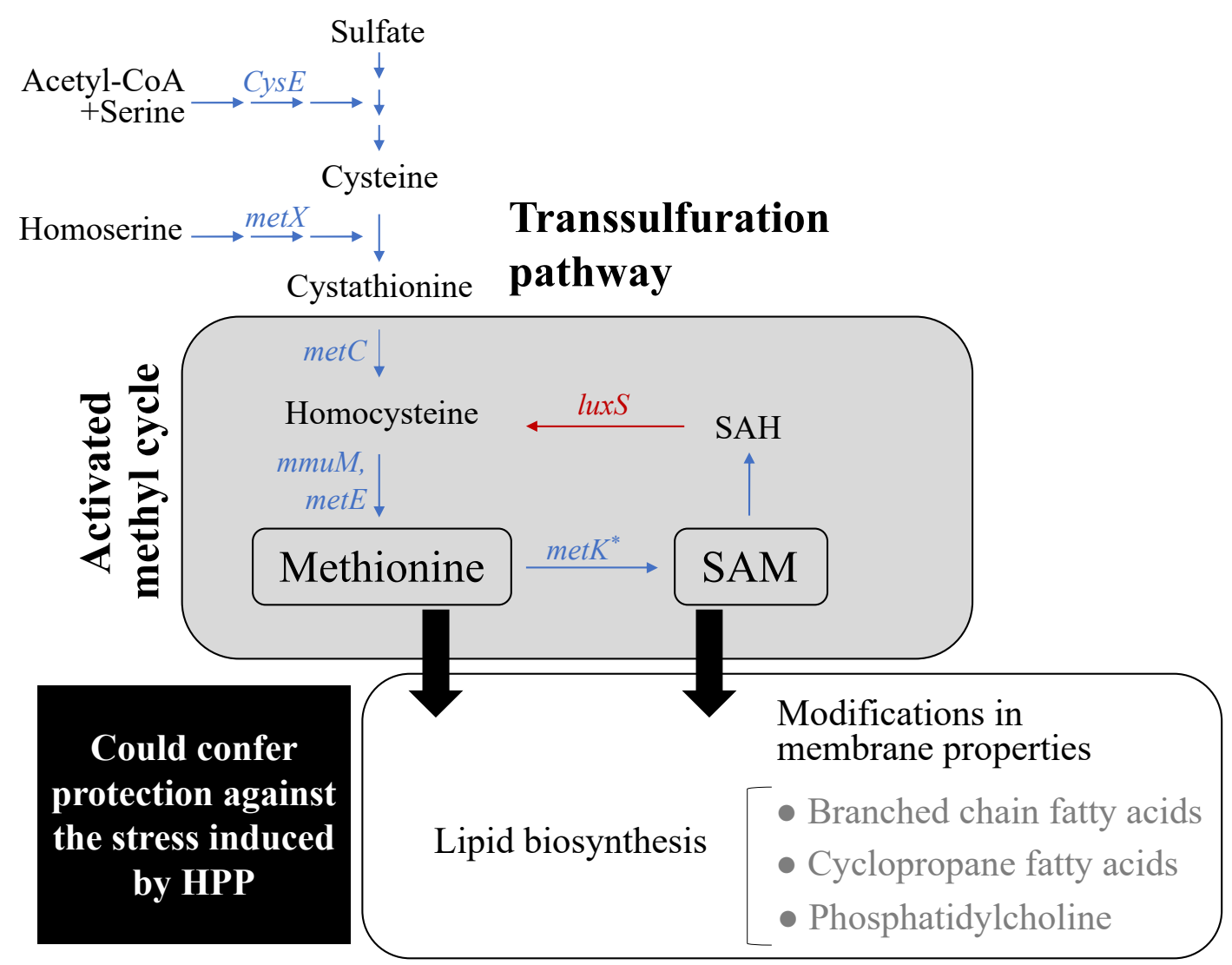

Figure 4. Predicted activation of the methyl cycle in L. monocytogenes CTC1034 and EGDe strains when exposed to lactate and its potential role on the piezo-protective effect exerted by lactate on L. monocytogenes stress induced by HPP. Blue and red arrows and text indicate genes that were upregulated and downregulated, respectively. Genes and proteins: $C y s E$, serine O-acetyltransferase; $m e t X$, homoserine O-acetyltransferase; metC, cysteine-S-conjugate beta-lyase; $m m u M$ and $m e t E$, homocysteine S-methyltransferases; metK, S-adenosylmethionine synthetase; luxS, S-ribosylhomocysteine lyase; $S A M$, S-adenosyl-methionine; $S A H$, S-adenosyl-homocysteine.

\subsubsection{Effect of HPP on L. monocytogenes}

The transcriptomic analysis revealed that both $L$. monocytogenes strains upregulated genes involved in DNA repair mechanisms such as RadA, phrB, uvrB, adaB, and lipid and peptidoglycan biosynthetic pathways ( $g l m S, \operatorname{murF}, m u r G, m u r C$, or $f a b H)$, among others (Supplementary Tables S2 and S7), presumably as a consequence of the stress induced by the application of the HPP to L. monocytogenes. In case of flagella assemblage (FlhA, FlhF, FliC, FliE, FliF, FliG, FliH, FliI, FliR, FliP, FlgB, FlgC, FlgD, FlgE, FlgG, FlgK and FlgL) and chemotaxis (MotA, CheA, CheR, CheY, FliG, FliM, and FliN/FliY), an upregulation of genes involved in these pathways was found in CTC1034 (Supplementary Table S2), while a downregulation was observed in EGDe (Supplementary Table S7). These differences could be related to the particularities of each L. monocytogenes strain but also to the higher severity of the HPP injury in the EGDe strain compared to CTC1034, leading to a higher inactivation extent (Figure 1). An important parameter influencing motility of L. monocytogenes is temperature; L. monocytogenes cells are motile at temperatures below $30{ }^{\circ} \mathrm{C}$ but not at human body temperature $\left(37^{\circ} \mathrm{C}\right)[56]$. Additionally, flagella, as cell surface appendices, are considered putative virulence factors. In the current study, the temperature for the experiments could partially explain the upregulation of the flagella genes in CTC1034. In addition to this, we may deduce that these genes would be downregulated when 
L. monocytogenes is under stress (for example desiccation) [57]. It is therefore puzzling that HPP resulted in an upregulation in CTC1034, and at this point we cannot provide a biological explanation. Nevertheless, this observation is particularly relevant since it suggests that cells of L. monocytogenes surviving the HPP treatment would be prepared to colonize the human body [58]. On the other hand, HPP was found to downregulate genes involved in the septal ring ( $f t s A, f t s W, f t s Q, m r e B)$. These results were in line with those reported by Bowman et al. [59] regarding the response of $L$. monocytogenes pressurized at 400-600 MPa for $5 \mathrm{~min}$ in tryptone soy yeast extract (TSYE) broth.

As a response to HPP, L. monocytogenes CTC1034 and EGDe upregulated genes involved in the methionine biosynthesis (luxS, mmuM, msrB), suggesting an enhanced methionine production/availability (Supplementary Tables S2 and S8), which also agrees with the enrichment gene analysis for EGDe (see Section 3.2.2). The upregulation of these genes pointed out that, as stated due to the exposure to lactate (Section 3.2.3), the application of HPP would result in a higher generation of SAM in L. monocytogenes, which could affect cellular processes throughout its role in the methyl cycle [60]. These results are in accordance with those reported by Bravim et al. [61], where it was found an upregulation of the sulfur metabolism genes involved in the activation of the methionine biosynthesis when Saccharomyces cerevisiae was submitted to an HPP of $50 \mathrm{MPa}$ for $30 \mathrm{~min}$.

Considering the metabolic pathways in which methionine and SAM are involved, methionine could increase L. monocytogenes resistance to HPP for its role as an endogenous antioxidant in cells [62] and for its involvement in lipid biosynthesis [63]. Since the HPP affects the bacterial membrane properties [64-66], the involvement of methionine in lipid biosynthesis could play a role in the HPP resistance (Figure 4). In this regard, according to the results of the fatty acid profile of L. monocytogenes CTC1034 (Table 1) compared with the control conditions when the pathogen was exposed to lactate and/or HPP stresses, cells tended to increase, although not significantly, the level of total branched-chain fatty acids (BCFAs, specifically iso and/or anteiso conformations of C13, C14, C15, C16, C17). This finding agrees with the fact that in L. monocytogenes BCFAs contribute to membrane fluidity and resistance against environmental stresses [67].

SAM was reported to be required for the synthesis of phosphatidylcholine from phosphatidylethanolamine [68] and to have a role in transferring a methylene group to mature phospholipids that lead to the formation of cyclopropane fatty acids (CFAs), a major component of the phospholipids of the bacterial membrane bilayers [69]. A higher proportion of CFAs in the membrane bilayer of Escherichia coli has been shown to increase the resistance of the pathogen submitted to HPP of $500 \mathrm{MPa}$ for 5 to $30 \mathrm{~min}$ [70]. Since the pressure resistance of $E$. coli is reported to be related to an altered membrane functionality and with the resistance of this pathogen to oxidative stress [71], it was suggested by Chen et al. [70] that CFAs could contribute to pressure resistance by increasing the resistance of membrane lipids to the oxidative stress derived from the application of the HPP. Therefore, the results of the present study point out that the exposure of L. monocytogenes cells to lactate prior the HPP would upregulate the methionine biosynthesis pathway, thus contributing to enhance the resistance against HPP by changes in the lipidic membrane functionality.

The higher expression of the methionine biosynthesis pathway by L. monocytogenes exposed to lactate and the inhibition of the biosynthesis of this amino acid by acetate reported for E. coli [50] could be the reason why the piezo-protective effect on L. monocytogenes treated at $400 \mathrm{MPa}$ for $10 \mathrm{~min}$ was only seen for cooked ham formulated with lactate and not with diacetate [10]. Further studies regarding L. monocytogenes membrane functionality (membrane composition, fluidity, and integrity) as a function of the exposure of lactate and the application of the HPP need to be conducted to experimentally to confirm the role of the membrane properties on the piezo-protective effect exerted by lactate on HPP inactivation of L. monocytogenes. 
Table 1. Fatty acid profile (mean $\% \pm$ standard deviation) of L. monocytogenes CTC1034 after exposure of cells to lactate, after the application of the HPP (400 MPa for $10 \mathrm{~min}$ ), and after the application of both stresses compared to control conditions (exposed to CHMM without lactate).

\begin{tabular}{|c|c|c|c|c|}
\hline \multirow{2}{*}{ Fatty Acid } & \multicolumn{4}{|c|}{ Condition } \\
\hline & Control & Lactate & HPP & Lactate + HPP \\
\hline C10:0 & $0.02 \pm 0.03$ & $0.09 \pm 0.12$ & $0.03 \pm 0.04$ & $0.08 \pm 0.01$ \\
\hline $\mathrm{C} 12: 0$ & $1.03 \pm 0.32$ & $0.87 \pm 0.07$ & $0.73 \pm 0.08$ & $0.77 \pm 0.03$ \\
\hline $\mathrm{C} 13$ iso & $0.12 \pm 0.01$ & $0.12 \pm 0.10$ & $0.06 \pm 0.00$ & $0.06 \pm 0.03$ \\
\hline C13 anteiso & $0.23 \pm 0.08$ & $0.27 \pm 0.06$ & $0.26 \pm 0.07$ & $0.26 \pm 0.06$ \\
\hline C14 iso & $1.26 \pm 0.01$ & $1.22 \pm 0.05$ & $1.22 \pm 0.15$ & $1.21 \pm 0.16$ \\
\hline C14 & $4.59 \pm 0.40$ & $3.99 \pm 0.61$ & $4.04 \pm 0.77$ & $3.99 \pm 0.89$ \\
\hline C15 iso & $14.05 \pm 0.83$ & $15.45 \pm 0.09$ & $14.31 \pm 0.28$ & $14.59 \pm 0.18$ \\
\hline C15 anteiso & $39.72 \pm 3.06$ & $41.78 \pm 1.28$ & $41.24 \pm 0.31$ & $41.14 \pm 0.45$ \\
\hline C15 & $0.42 \pm 0.18$ & $0.49 \pm 0.06$ & $0.51 \pm 0.05$ & $0.51 \pm 0.12$ \\
\hline $\mathrm{C} 16$ iso & $3.13 \pm 0.03$ & $3.26 \pm 0.35$ & $3.60 \pm 0.58$ & $3.40 \pm 0.21$ \\
\hline C16 & $5.90 \pm 2.51$ & $4.17 \pm 0.38$ & $4.29 \pm 0.60$ & $4.03 \pm 0.15$ \\
\hline C16:1 & $2.62 \pm 0.00$ & $2.44 \pm 1.19$ & $2.79 \pm 0.86$ & $2.63 \pm 0.58$ \\
\hline $\mathrm{C} 17$ iso & $4.63 \pm 0.35$ & $4.82 \pm 0.05$ & $5.23 \pm 0.07$ & $5.06 \pm 0.20$ \\
\hline C17 anteiso & $16.75 \pm 1.39$ & $17.28 \pm 0.60$ & $17.91 \pm 0.73$ & $18.10 \pm 0.53$ \\
\hline C18 & $1.72 \pm 0.71$ & $1.11 \pm 0.11$ & $1.12 \pm 0.13$ & $1.38 \pm 0.05$ \\
\hline C18:1 cis9 & $3.31 \pm 1.28$ & $2.33 \pm 0.10$ & $2.40 \pm 0.21$ & $2.39 \pm 0.17$ \\
\hline C18:1 cis11 & $0.02 \pm 0.03$ & $0.04 \pm 0.05$ & $0.01 \pm 0.02$ & $0.00 \pm 0.00$ \\
\hline C19:0 & $0.11 \pm 0.04$ & $0.08 \pm 0.01$ & $0.09 \pm 0.01$ & $0.26 \pm 0.10$ \\
\hline C18:2 & $0.36 \pm 0.17$ & $0.20 \pm 0.09$ & $0.17 \pm 0.14$ & $0.16 \pm 0.10$ \\
\hline BCFA $^{a}$ & $79.89 \pm 5.67$ & $84.20 \pm 1.57$ & $83.82 \pm 0.59$ & $83.82 \pm 0.24$ \\
\hline iso BCFA & $23.19 \pm 1.15$ & $24.88 \pm 0.36$ & $24.41 \pm 0.52$ & $24.31 \pm 0.37$ \\
\hline anteiso BCFA & $56.70 \pm 4.53$ & $59.32 \pm 1.93$ & $59.41 \pm 1.12$ & $59.50 \pm 0.13$ \\
\hline iso/anteiso & $0.41 \pm 0.02$ & $0.42 \pm 0.02$ & $0.41 \pm 0.02$ & $0.41 \pm 0.01$ \\
\hline C13 BCFA & $0.35 \pm 0.07$ & $0.39 \pm 0.04$ & $0.32 \pm 0.08$ & $0.32 \pm 0.02$ \\
\hline C15 BCFA & $53.77 \pm 3.89$ & $57.23 \pm 1.37$ & $55.55 \pm 0.59$ & $55.73 \pm 0.63$ \\
\hline C17 BCFA & $21.38 \pm 1.74$ & $22.10 \pm 0.65$ & $23.14 \pm 0.66$ & $23.16 \pm 0.73$ \\
\hline C15 BCFA/C17 BCFA & $2.51 \pm 0.02$ & $2.59 \pm 0.01$ & $2.40 \pm 0.05$ & $2.41 \pm 0.10$ \\
\hline C15 anteiso /C17 anteiso & $2.37 \pm 0.01$ & $2.42 \pm 0.01$ & $2.31 \pm 0.08$ & $2.27 \pm 0.09$ \\
\hline
\end{tabular}

The increased expression of the methionine pathway by L. monocytogenes CTC1034 under HPP stress could explain, at least partially, the piezo-stimulation effect (which was enhanced by the presence of lactate) in the growth rate of L. monocytogenes CTC1034 cells surviving a HPP at $600 \mathrm{MPa}$ for 3 min observed by Bover-Cid et al. [11]. Since methionine is a key amino acid involved in enabling cell proliferation as precursor of anabolic pathways [72], the upregulation of the methionine biosynthesis due to lactate and HPP stresses could help L. monocytogenes cells to repair cellular membrane and enhance their subsequent proliferation. Nevertheless, further studies should be conducted to complement and support this.

\section{Conclusions}

New insights are provided regarding the molecular mechanisms underlying the protective effect of lactate on L. monocytogenes submitted to HPP. The short exposure of L. monocytogenes cells to lactate promoted a shift in the pathogen's central metabolism, favoring the propanediol and ethanolamine pathways together with the synthesis of the B12 cofactor, which could confer a competitive advantage for L. monocytogenes to overcome the stress suffered by HPP. Changes to the central metabolism, together with responses involving the modification of the intracellular pool of anions or $\mathrm{pH}$ homeostasis such as glutamate metabolism or enrichment of flagellar assembly pathways could constitute mechanisms responsible for the piezo-protective effect of lactate. The upregulation of the methionine synthesis pathway after exposure to lactate could also be relevant in relation to the piezo-resistance mechanisms through changes in the properties of the cytoplasmic 
membrane and its ability to cope with pressure stress. Further studies regarding the $L$. monocytogenes membrane functionality (membrane composition, fluidity, and integrity) as a function of the exposure of lactate and the application of the HPP need to be conducted to experimentally confirm the role of the membrane properties on the piezo-protection and piezo-stimulation effect exerted by lactate on HPP inactivation of L. monocytogenes.

Supplementary Materials: The following are available online at https://www.mdpi.com/article/10 $.3390 /$ biom $11050677 /$ s1, Table S1: Number of raw and clean reads from the transcriptomic analysis of both L. monocytogenes strains CTC1034 and EGDe in CHMM without and with lactate and/or without and with HPP of $400 \mathrm{MPa}$ for $10 \mathrm{~min}$, Table S2: List of KEGG Orthology (KO) genes differentially (FDR < 0.05) expressed in the L. monocytogenes strain CTC1034 in samples without lactate pressurized and non-pressurized. Positive Log2 fold change indicates genes more abundant in pressurized samples, Table S3: List of KEGG Orthology $(\mathrm{KO})$ genes differentially (FDR < 0.05) expressed in the L. monocytogenes CTC1034 strain in non-pressurized samples without and with lactate. Positive Log2 fold change indicates genes more abundant in samples with lactate, Table S4: List of KEGG Orthology $(\mathrm{KO})$ genes differentially (FDR <0.05) expressed in the L. monocytogenes strain CTC1034 in pressurized samples without and with lactate. Negative Log2 fold change indicates genes less abundant in samples with lactate, Table S5: List of KEGG Orthology (KO) genes differentially (FDR < 0.05) expressed in the L. monocytogenes strain CTC1034 in samples with lactate non-pressurized and pressurized. Positive Log2 fold change indicates genes more abundant in pressurized samples, Table S6: List of KEGG Orthology (KO) genes differentially (FDR < 0.05) expressed in CTC1034 L. monocytogenes strain throughout the comparison of control samples (non-exposed to lactate and nonpressurized) to samples exposed to lactate and pressurized. Positive Log2 fold change indicates genes more abundant in samples exposed to lactate and pressurized, Table S7: List of KEGG Orthology (KO) genes differentially (FDR $<0.05$ ) expressed in the L. monocytogenes strain EGDe in samples without lactate pressurized and non-pressurized. Positive Log2 fold change indicates genes more abundant in pressurized samples, Table S8: List of KEGG Orthology (KO) genes differentially (FDR < 0.05) expressed in the L. monocytogenes strain EGDe in pressurized samples without and with lactate. Positive Log2 fold change indicates genes more abundant in samples with lactate, Table S9: List of KEGG Orthology $(\mathrm{KO})$ genes differentially (FDR < 0.05) expressed in the L. monocytogenes strain EGDe in samples with lactate non-pressurized and pressurized. Positive Log2 fold change indicates genes more abundant in pressurized samples, Table S10: List of KEGG Orthology (KO) genes differentially (FDR < 0.05) expressed in EGDe L. monocytogenes strain throughout the comparison of control samples (non-exposed to lactate and non-pressurized) to samples exposed to lactate and pressurized. Positive Log2 fold change indicates genes more abundant in samples exposed to lactate and pressurized.

Author Contributions: Conceptualization: A.J., S.B.-C. and K.R.; Data curation: C.S.-C. and I.F.; Formal analysis: C.S.-C. and I.F.; Funding acquisition: L.C., S.B.-C. and K.R.; Investigation: C.S.-C., I.F. and A.J.; Methodology: C.S.-C., A.J., S.B.-C. and K.R.; Project administration: A.J.; Resources: L.C., S.B.-C. and K.R.; Software: I.F.; Supervision: L.C., S.B.-C. and K.R.; Validation: L.C.; Writing-original draft, C.S.-C., I.F., A.J. and S.B.-C.; Writing-review \& editing: A.J., S.B.-C. and K.R. All authors have read and agreed to the published version of the manuscript.

Funding: This research was supported by the Consolidated Research Group grant (2017 SGR 1650) and the CERCA Programme/Generalitat de Catalunya.

Institutional Review Board Statement: Not applicable.

Informed Consent Statement: Not applicable.

Data Availability Statement: WGS and Metatranscriptomic raw sequence reads were deposited at the Sequence Read Archive of the National Center for Biotechnology Information (Bioproject accession number: PRJNA692371 and PRJNA692360, for L. monocytogenes CTC1034 and EGDe, respectively).

Acknowledgments: Cristina Serra-Castelló thanks the International Committee on Food Microbiology and Hygiene (ICFMH) for the short-term mobility grant.

Conflicts of Interest: The authors declare no conflict of interest. 


\section{References}

1. FDA; USDA. Interagency Risk Assessment: Listeria Monocytogenes in Retail Delicatessens; Technical report; U.S. Department of Agriculture. Food Safety and Inspection Service: Washington, DC, USA, 2013.

2. EFSA Commission Regulation (EC) No 2073/2005 of 15th November 2005 on microbiological criteria for foodstuffs. Off. J. Eur. Union 2005, L338, 1-26.

3. FSIS 9 CFR Part 430: Control of Listeria monocytogenes in ready-to-eat meat and poultry products. Fed. Regist. 2003, 68, 34208-34254.

4. Jofré, A.; Garriga, M.; Aymerich, T. Inhibition of Salmonella sp. Listeria monocytogenes and Staphylococcus aureus in cooked ham by combining antimicrobials, high hydrostatic pressure and refrigeration. Meat Sci. 2008, 78, 53-59. [CrossRef]

5. Barmpalia, I.M.; Koutsoumanis, K.P.; Geornaras, I.; Belk, K.E.; Scanga, J.A.; Kendall, P.A.; Smith, G.C.; Sofos, J.N. Effect of antimicrobials as ingredients of pork bologna for Listeria monocytogenes control during storage at 4 or $10{ }^{\circ} \mathrm{C}$. Food Microbiol. 2005, 22, 205-211. [CrossRef]

6. Theron, M.M.; Lues, J.F.R. Organic Acids and Meat Preservation: A Review. Food Rev. Int. 2007, 23, 141-158. [CrossRef]

7. Leistner, L. Basic aspects of food preservation by hurdle technology. Int. J. Food Microbiol. 2000, 55, 181-186. [CrossRef]

8. Capozzi, V.; Fiocco, D.; Amodio, M.L.; Gallone, A.; Spano, G. Bacterial stressors in minimally processed food. Int. J. Mol. Sci. 2009, 10, 3076-3105. [CrossRef] [PubMed]

9. Lerasle, M.; Guillou, S.; Simonin, H.; Anthoine, V.; Chéret, R.; Federighi, M.; Membré, J.-M. Assessment of Salmonella and Listeria monocytogenes level in ready-to-cook poultry meat: Effect of various high pressure treatments and potassium lactate concentrations. Int. J. Food Microbiol. 2014, 186, 74-83. [CrossRef]

10. Serra-Castelló, C.; Jofré, A.; Belletti, N.; Garriga, M.; Bover-Cid, S. Modelling the piezo-protection effect exerted by lactate on the high pressure resistance of Listeria monocytogenes in cooked ham. Food Res. Int. 2021, 140, 110003. [CrossRef]

11. Bover-Cid, S.; Serra-Castelló, C.; Dalgaard, P.; Garriga, M.; Jofré, A. New insights on Listeria monocytogenes growth in pressurised cooked ham: A piezo-stimulation effect enhanced by organic acids during storage. Int. J. Food Microbiol. 2019, 290, 150-158. [CrossRef]

12. Gorski, L.; Flaherty, D.; Mandrell, R.E. Competitive Fitness of Listeria monocytogenes Serotype 1/2a and 4b Strains in Mixed Cultures with and without Food in the U.S. Food and Drug Administration Enrichment Protocol. Appl. Environ. Microbiol. 2006, 72, 776-783. [CrossRef]

13. Aymerich, T.; Jofré, A.; Garriga, M.; Hugas, M. Inhibition of Listeria monocytogenes and Salmonella by natural antimicrobials and high hydrostatic pressure in sliced cooked ham. J. Food Prot. 2005, 68, 173-177. [CrossRef]

14. Hereu, A. Modeling the high pressure inactivation kinetics of Listeria monocytogenes on RTE cooked meat products. Innov. Food Sci. Emerg. Technol. 2012, 16, 305-315. [CrossRef]

15. Hereu, A.; Bover-Cid, S.; Garriga, M.; Aymerich, T. High hydrostatic pressure and biopreservation of dry-cured ham to meet the Food Safety Objectives for Listeria monocytogenes. Int. J. Food Microbiol. 2012, 154, 107-112. [CrossRef]

16. Morales, P.; Calzada, J.; Rodríguez, B.; de Paz, M.; Gaya, P.; Nuñez, M. Effect of cheese water activity and carbohydrate content on the barotolerance of Listeria monocytogenes scott A. J. Food Prot. 2006, 69, 1328-1333. [CrossRef]

17. Jantzen, M.M.; Navas, J.; De Paz, M.; Rodríguez, B.; Da Silva, W.P.; Nuñez, M.; Martínez-Suárez, J.V. Evaluation of ALOA plating medium for its suitability to recover high pressure-injured Listeria monocytogenes from ground chicken meat. Lett. Appl. Microbiol. 2006, 43, 313-317. [CrossRef]

18. Cocolin, L.; Manzano, M.; Aggio, D.; Cantoni, C.; Comi, G. A novel polymerase chain reaction (PCR)-denaturing gradient gel electrophoresis (DGGE) for the identification of Micrococcaceae strains involved in meat fermentations. Its application to naturally fermented Italian sausages. Meat Sci. 2001, 58, 59-64. [CrossRef]

19. Langmead, B.; Salzberg, S.L. Fast gapped-read alignment with Bowtie 2. Nat. Methods 2012, 9, 357-359. [CrossRef]

20. Schmieder, R.; Edwards, R. Quality control and preprocessing of metagenomic datasets. Bioinformatics 2011, 27, 863-864. [CrossRef]

21. Bankevich, A.; Nurk, S.; Antipov, D.; Gurevich, A.A.; Dvorkin, M.; Kulikov, A.S.; Lesin, V.M.; Nikolenko, S.I.; Pham, S.; Prjibelski, A.D.; et al. SPAdes: A new genome assembly algorithm and its applications to single-cell sequencing. J. Comput. Biol. 2012, 19, 455-477. [CrossRef]

22. Seemann, T. Prokka: Rapid prokaryotic genome annotation. Bioinformatics 2014, 30, 2068-2069. [CrossRef]

23. Page, A.J.; Cummins, C.A.; Hunt, M.; Wong, V.K.; Reuter, S.; Holden, M.T.G.; Fookes, M.; Falush, D.; Keane, J.A.; Parkhill, J. Roary: Rapid large-scale prokaryote pan genome analysis. Bioinformatics 2015, 31, 3691-3693. [CrossRef] [PubMed]

24. Mitra, S.; Stärk, M.; Huson, D.H. Analysis of 16S rRNA environmental sequences using MEGAN. BMC Genom. 2011, 12 , S17. [CrossRef]

25. Anders, S.; Huber, W. Differential expression analysis for sequence count data. Genome Biol. 2010, 11, R106. [CrossRef]

26. R Core Team. R: A Language and Environment for Statistical Computing; R Core: Vienna, Austria, 2019.

27. Luo, W.; Friedman, M.S.; Shedden, K.; Hankenson, K.D.; Woolf, P.J. GAGE: Generally applicable gene set enrichment for pathway analysis. BMC Bioinform. 2009, 10, 161. [CrossRef] [PubMed]

28. Castro-Gómez, P.; Fontecha, J.; Rodríguez-Alcalá, L.M. A high-performance direct transmethylation method for total fatty acids assessment in biological and foodstuff samples. Talanta 2014, 128, 518-523. [CrossRef] [PubMed] 
29. Calvo, M.V.; Martín-Hernández, M.C.; García-Serrano, A.; Castro-Gómez, M.P.; Alonso-Miravalles, L.; García-Martín, R.; MeginoTello, J.; Alonso, L.; Fontecha, J. Comprehensive characterization of neutral and polar lipids of buttermilk from different sources and its milk fat globule membrane isolates. J. Food Compos. Anal. 2020, 86, 103386. [CrossRef]

30. Jofré, A.; Garriga, M.; Aymerich, T. Inhibition of Listeria monocytogenes in cooked ham through active packaging with natural antimicrobials and high-pressure processing. J. Food Prot. 2007, 70, 2498-2502. [CrossRef] [PubMed]

31. Stollewerk, K.; Jofré, A.; Comaposada, J.; Arnau, J.; Garriga, M. NaCl-free processing, acidification, smoking and high pressure: Effects on growth of Listeria monocytogenes and Salmonella enterica in QDS processed®dry-cured ham. Food Control 2014, 35, 56-64. [CrossRef]

32. Jofré, A.; Champomier-Vergès, M.; Anglade, P.; Baraige, F.; Martín, B.; Garriga, M.; Zagorec, M.; Aymerich, T. Protein synthesis in lactic acid and pathogenic bacteria during recovery from a high pressure treatment. Res. Microbiol. 2007, 158, 512-520. [CrossRef]

33. Stasiewicz, M.J.; Wiedmann, M.; Bergholz, T.M. The transcriptional response of Listeria monocytogenes during adaptation to growth on lactate and diacetate includes synergistic changes that increase fermentative acetoin production. Appl. Environ. Microbiol. 2011, 77, 5294-5306. [CrossRef] [PubMed]

34. Carpenter, C.E.; Broadbent, J.R. External concentration of organic acid anions and pH: Key independent variables for studying how organic acids inhibit growth of bacteria in mildly acidic foods. J. Food Sci. 2009, 74, R12-5. [CrossRef]

35. Mellin, J.R.; Tiensuu, T.; Bécavin, C.; Gouin, E.; Johansson, J.; Cossart, P. A riboswitch-regulated antisense RNA in Listeria monocytogenes. Proc. Natl. Acad. Sci. USA 2013, 110, 13132-13137. [CrossRef]

36. Xue, J.; Murrieta, C.M.; Rule, D.C.; Miller, K.W. Exogenous or L-Rhamnose-derived 1,2-Propanediol is metabolized via a pduD-dependent pathway in Listeria innocua. Appl. Environ. Microbiol. 2008, 74, 7073-7079. [CrossRef]

37. Tang, S.; Orsi, R.H.; den Bakker, H.C.; Wiedmann, M.; Boor, K.J.; Bergholz, T.M. Transcriptomic analysis of the adaptation of Listeria monocytogenes to growth on vacuum-packed cold smoked salmon. Appl. Environ. Microbiol. 2015, 81, 6812-6824. [CrossRef] [PubMed]

38. Anast, J.M.; Schmitz-Esser, S. The transcriptome of Listeria monocytogenes during co-cultivation with cheese rind bacteria suggests adaptation by induction of ethanolamine and 1,2-propanediol catabolism pathway genes. PLoS ONE 2020, 15, e0233945. [CrossRef] [PubMed]

39. Zeng, Z.; Smid, E.J.; Boeren, S.; Notebaart, R.A.; Abee, T. Bacterial microcompartment-dependent 1,2-Propanediol utilization stimulates anaerobic growth of Listeria monocytogenes EGDe. Front. Microbiol. 2019, 10, 2660. [CrossRef]

40. Bucur, F.I.; Grigore-Gurgu, L.; Crauwels, P.; Riedel, C.U.; Nicolau, A.I. Resistance of Listeria monocytogenes to stress conditions encountered in food and food processing environments. Front. Microbiol. 2018, 9, 2700. [CrossRef] [PubMed]

41. Roe, A.J.; McLaggan, D.; Davidson, I.; O'Byrne, C.; Booth, I.R. Perturbation of anion balance during inhibition of growth of Escherichia coli by weak acids. J. Bacteriol. 1998, 180, 767-772. [CrossRef] [PubMed]

42. Feehily, C.; O’Byrne, C.P.; Karatzas, K.A.G. Functional $\gamma$-aminobutyrate shunt in Listeria monocytogenes: Role in acid tolerance and succinate biosynthesis. Appl. Environ. Microbiol. 2013, 79, 74-80. [CrossRef]

43. Gabel, C.V.; Berg, H.C. The speed of the flagellar rotary motor of Escherichia coli varies linearly with protonmotive force. Proc. Natl. Acad. Sci. USA 2003, 100, 8748-8751. [CrossRef]

44. Porter, S.L.; Wadhams, G.H.; Armitage, J.P. Signal processing in complex chemotaxis pathways. Nat. Rev. Microbiol. 2011, 9, 153-165. [CrossRef]

45. Lado, B.H.; Yousef, A.E. Characteristics of Listeria monocytogenes important to food processors. In Listeria, Listeriosis, and Food Safety; Ryser, E., Marth, E., Eds.; CRC Press: Boca Raton, FL, USA, 2007; pp. 157-213.

46. Brul, S.; Coote, P. Preservative agents in foods: Mode of action and microbial resistance mechanisms. Int. J. Food Microbiol. 1999, 50, 1-17. [CrossRef]

47. Doores, S. Organic acids. In Antimicrobials in Food; Davidson, P., Sofos, J., Branen, A., Eds.; CRC Press: Boca Raton, FL, USA, 2005; pp. 91-141.

48. Ten Brink, B.; Otto, R.; Hansen, U.P.; Konings, W.N. Energy recycling by lactate efflux in growing and nongrowing cells of Streptococcus cremoris. J. Bacteriol. 1985, 162, 383-390. [CrossRef]

49. Suo, Y.; Gao, S.; Baranzoni, G.M.; Xie, Y.; Liu, Y. Comparative transcriptome RNA-Seq analysis of Listeria monocytogenes with sodium lactate adaptation. Food Control 2018, 91, 193-201. [CrossRef]

50. Roe, A.J.; O'Byrne, C.; McLaggan, D.; Booth, I.R. Inhibition of Escherichia coli growth by acetic acid: A problem with methionine biosynthesis and homocysteine toxicity. Microbiology 2002, 148, 2215-2222. [CrossRef]

51. Pinhal, S.; Ropers, D.; Geiselmann, J.; de Jong, H. Acetate metabolism and the inhibition of bacterial growth by acetate. J. Bacteriol. 2019, 201, e00147-19. [CrossRef] [PubMed]

52. Ferla, M.P.; Patrick, W.M. Bacterial methionine biosynthesis. Microbiology 2014, 160, 1571-1584. [CrossRef]

53. Walvekar, A.S.; Laxman, S. Methionine at the heart of anabolism and signaling: Perspectives from Budding Yeast. Front. Microbiol. 2019, 10, 2624. [CrossRef]

54. Aktas, M.; Gleichenhagen, J.; Stoll, R.; Narberhaus, F. S-adenosylmethionine-binding properties of a bacterial phospholipid N-methyltransferase. J. Bacteriol. 2011, 193, 3473-3481. [CrossRef]

55. Loi, V.V.; Rossius, M.; Antelmann, H. Redox regulation by reversible protein S-thiolation in bacteria. Front. Microbiol. 2015, 6, 187. [CrossRef] 
56. Gründling, A.; Burrack, L.S.; Bouwer, H.G.A.; Higgins, D.E. Listeria monocytogenes regulates flagellar motility gene expression through MogR, a transcriptional repressor required for virulence. Proc. Natl. Acad. Sci. USA 2004, 101, 12318-12323. [CrossRef] [PubMed]

57. Hingston, P.A.; Piercey, M.J.; Truelstrup Hansen, L. Genes associated with desiccation and osmotic stress in Listeria monocytogenes as revealed by insertional mutagenesis. Appl. Environ. Microbiol. 2015, 81, 5350-5362. [CrossRef]

58. O'Neil, H.S.; Marquis, H. Listeria monocytogenes flagella are used for motility, not as adhesins, to increase host cell invasion. Infect. Immun. 2006, 74, 6675-6681. [CrossRef] [PubMed]

59. Bowman, J.P.; Bittencourt, C.R.; Ross, T. Differential gene expression of Listeria monocytogenes during high hydrostatic pressure processing. Microbiology 2008, 154, 462-475. [CrossRef]

60. Parveen, N.; Cornell, K.A. Methylthioadenosine/S-adenosylhomocysteine nucleosidase, a critical enzyme for bacterial metabolism. Mol. Microbiol. 2011, 79, 7-20. [CrossRef] [PubMed]

61. Bravim, F.; da Silva, L.F.; Souza, D.T.; Lippman, S.I.; Broach, J.R.; Fernandes, A.A.R.; Fernandes, P.M.B. High hydrostatic pressure activates transcription factors involved in Saccharomyces cerevisiae stress tolerance. Curr. Pharm. Biotechnol. 2012, 13, 2712-2720. [CrossRef]

62. Luo, S.; Levine, R.L. Methionine in proteins defends against oxidative stress. FASEB J. Off. Publ. Fed. Am. Soc. Exp. Biol. 2009, 23, 464-472. [CrossRef]

63. O'Leary, W.M. Involvement of methionine in bacterial lipid synthesis. J. Bacteriol. 1959, 78, 709-713. [CrossRef]

64. Cheftel, J.C. Review: High-pressure, microbial inactivation and food preservation. Food Sci. Technol. Int. 1995, 1, 75-90. [CrossRef]

65. Macdonald, A.G. The effects of pressure on the molecular structure and physiological functions of cell membranes. Philos. Trans. R. Soc. London. Ser. B Biol. Sci. 1984, 304, 47-68. [CrossRef]

66. Brooks, N.J. Pressure effects on lipids and bio-membrane assemblies. IUCrJ 2014, 1, 470-477. [CrossRef] [PubMed]

67. Sun, Y.; O'Riordan, M.X.D. Branched-chain fatty acids promote Listeria monocytogenes intracellular infection and virulence. Infect. Immun. 2010, 78, 4667-4673. [CrossRef]

68. Geiger, O.; López-Lara, I.M.; Sohlenkamp, C. Phosphatidylcholine biosynthesis and function in bacteria. Biochim. Biophys. Acta Mol. Cell Biol. Lipids. 2013, 1831, 503-513. [CrossRef] [PubMed]

69. Grogan, D.W.; Cronan, J.E.J. Cyclopropane ring formation in membrane lipids of bacteria. Microbiol. Mol. Biol. Rev. 1997, 61, 429-441. [CrossRef]

70. Chen, Y.Y.; Gänzle, M.G. Influence of cyclopropane fatty acids on heat, high pressure, acid and oxidative resistance in Escherichia coli. Int. J. Food Microbiol. 2016, 222, 16-22. [CrossRef]

71. Gänzle, M.; Liu, Y. Mechanisms of pressure-mediated cell death and injury in Escherichia coli: From fundamentals to food applications. Front. Microbiol. 2015, 6, 599. [CrossRef] [PubMed]

72. Jochim, A.; Shi, T.; Belikova, D.; Schwarz, S.; Peschel, A.; Heilbronner, S. Methionine limitation impairs pathogen expansion and biofilm formation capacity. Appl. Environ. Microbiol. 2019, 85, e00177-19. [CrossRef] [PubMed] 